\title{
Advances in operative techniques
}

\section{Advancement-onlay: an improved technique of fronto-orbital remodeling in craniosynostosis *}

\author{
Steven R. Cohen ${ }^{1}$, Henry K. Kawamoto, Jr. ${ }^{2}$, Fernando Burstein ${ }^{4}$, and Warwick J. Peacock ${ }^{3}$ \\ ${ }^{1}$ Section of Plastic and Reconstructive Surgery, University of Michigan, Taubman Center No. 2130, 1500 East Medical Drive, \\ Ann Arbor, MI 48109-0340, USA \\ ${ }^{2}$ Division of Plastic and Reconstructive Surgery and ${ }^{3}$ Division of Neurosurgery, UCLA Medical Center, Los Angeles, California, USA \\ ${ }^{4}$ Division of Plastic and Reconstructive Surgery, Scottish Rites Children's Hospital, Atlanta, Georgia, USA
}

Received September 24, 1990/Revised February 12, 1991

\begin{abstract}
Eighteen patients with nonsyndromic craniosynostosis underwent fronto-orbital remodeling with an advancement-onlay technique. The mean age of the infants was 5 months (range $=2-11$ months) when the procedure was performed for the following indications: unilateral coronal synostosis $(n=10)$; bilateral coronal synostosis $(n=3)$; metopic synostosis $(n=2)$; and multiple craniosynostoses $(n=3)$. The technique consists of (1) unilateral or bifrontal craniotomy, (2) superior orbital rim rocontouring and advancement, and (3) frontal bone graft rotation and onlay. Posteriorly, the frontal bone graft is left "floating," while anteriorly, rigid fixation with microplates and screws has supplanted wire osteosynthesis. The use of rigid fixation prevents uncontrotled "float" of the forchead and eliminates the need for temporal struts. Follow-up time ranged from 6 to 60 months (mean $=2.6$ years). There were no serious postoperative complications. Surgical results were good to excellent in $94 \%$ of cases and poor to fair in $6 \%$. Only 1 patient with a Kleeblattschädel deformity required major revision, while another patient with trigonocephaly underwent a minor, extracranial recontouring procedure. Supraorbital rim and /or forehead recession suggestive of relapse or initial inadequacy of anterior projection occurred in 3 patients $(17 \%)$. Residual, mild contour abnormalities of the forehead and/or temporal regions were found in 5 cases. To dale, no gross disturbances in craniofacial growth related to our method of rigid fixation have been observed and no clinically detcctable resynostosis has occurred.
\end{abstract}

Key words: Advancement-onlay - Fronto-orbital remodeling - Craniosynostosis

Most authors would agree that in the absence of increased intracranial pressure, the goal of treatment of

\footnotetext{
* Presented at the 69th Annual Meeting of the American Association of Plastic Surgeons, Hot Springs, Virginia, 1990
}

Offprint requests to: S. R. Cohen craniosynostosis is to produce normal calvarial shape and facial dimensions [2, 9, 12]. Longitudinal, threedimensional computed tomography (CT) studies of nonsyndromal solitary and bicoronal synostosis have shown normalization of endocranial anatomy, confirming the efficacy of cranio-orbital operations [5-8]. Lesser degrees of normalization occur in patients with multiple synostoses [5].

Improvement in exocranial or surface anatomy generally accompanies correction of osseous abnormalities. However, precise data quantifying postoperative changes in surface morphology are not yet available, making it diflicult to compare the myriad of results reported by different centers [7]. In a two-center study, Bartlett et al. analyzed late results in 48 patients undergoing either unilateral or bilateral fronto-orbital remodeling for unilateral coronal synostosis [1]. Aesthetic outcome was good to excellent in over $75 \%$ of patients, regardless of the type of procedure [1]. However, on detailed inspection, they found residual irregularities of the ipsilateral temporal and/or lateral forehead in the majority of cases [1].

We, too, have observed less than ideal results, consisting of supralateral orbital rim and/or forehead recession in selected patients with nonsyndromic craniosynostosis. Concern about possible early relapse or initial inadequacy of anterior projection of the superior orbital har led to the development of an improved and simplified technique: advancement-onlay.

The technique consists of a (1) unilateral or bifrontal craniotomy, (2) superior orbital rim recontouring and advancement, and (3) frontal bone graft rotation, remodelling, and onlay (see Figs. 2-8). The frontal bone is left "floating," free of any posterior fixation [3]. Anteriorly, where relapse, segment shifts, or cephalic "floating" may occur with closure of the coronal flap, rigid fixation with microplates and screws has supplanted wire osteosynthesis. Midline resection of the deformed metopic suture and cranial vault reshaping are performed for trigonocephaly and multiple synosloses, respectively.

In essence, our technique combines contemporary fronto-orbital remodeling with a "throw-back" to the 
original onlay technique utilized by Rougerie [4]. Herein, we describe its application in 18 paticnts treated from 1985 to 1990 at the UCLA Medical Center.

\section{Materials and methods}

Patients with craniosynostosis are seen in joint consultation by a plastic surgeon and pediatric neurosurgeon. Plain films of the skull and face are routinely ordered. CT scans are obtained to rule out underlying neutologic abnormality.

Like others, we prefer to intervene within the first 6 months of life and capitalize on early, rapid brain growth to promote calvarial expansion and remodeling [10]. Midface retrusion is treated secondarily at 4 to 6 years of age, at which time either a LeFort III or monoblock advancement is performed, depending on the morphoogy of the residual deformity.

\section{Types of deformities and operative techniques}

\section{Unilateral coronal symostosis (plagiocephaty)}

Our surgical approach consists of extended frontal craniotomy and superior orbital bar advancement (Figs. 2-4). Thus, rather than arbitrarily selecting either unilateral or bilateral orbital advancement and forehead reshaping, a frontal craniotomy is designed to encompass the ipsilateral flattened area, extending contralaterally to where the forehead appears normal (Fig. 4).

A superior orbital osteotony is made approximately $1 \mathrm{~cm}$ above the orbital roof and carried across the midline to include the portion of the contralateral superior orbital rim that is recessed or otherwise deformed. Recently, we have angled the ostcotomy superiorly in the vicinity of the future frontal sinus (sinus sparing osteotomy) to avoid compromise of its subsequent development (Fig. 2).

In milder cases of plagiocephaly, where contralateral bossing is limited and orbital deformation is negligible, the frontal craniotomy and orbital osteotomy are confined to the affected side. Thus, the bony cuts are tailored to the topography of the defonnity (Fig. 3).

The use of rigid microplate and screw fixation has obviated the need for creating tongue-in-groove extensions into the temporal fossa. Temporal osteotomies are now electively performed to correct bony depressions and are not considered a necessity for stabilization of the superior orbital bony fragment.

Recontouring of the superior orbital rim is achieved by standard techniques. Incomplete vertical cuts and/or effacement of the bone on its posterior surface facilitate bending of the superior orbital bar. The recontoured rim is then symmetrically repositioned and secured with microplates and screws at the vertical limb of the supcrior orbital osteotomy and at the lateral orbital osteotomy (Fig. 2).

The detached frontal bone is remodeled and rotated to provide the best contour and then onlayed over the adwanced superior orbital bar. Cutouts are made to correspond to the curvature of the superior orbital rim (Fig. 2). Microscrews sunk in a tandem (position) fastion secure the frontal onlay in place, adapting the underlying superior orbital bar to the onlay's shape. Posteriorly, the frontal bone graft is left "floating."

Prior to wound closure, the ipsilateral superior orbital roof is bone grafted, obliterating the "harlequin" configuration. The lateral canthus is resuspended if it had been detached during the procedure. The contralateral brow is lifted to equalize the level of the cycbrows.

\section{Bilateral coronal synostosis (brachycephaly)}

Our operative approach to patients with bilateral coronal synostosis consists of bifrontal craniotomy with bilateral recontouring and advancement of the superior orbital bar (Fig. 5). Temporal extensions are made not so much for purposes of fixation, but rather to improve the contour of the temporal region. The advanced superior orbital rims are fixed with microplates and screws at the frontonasal junction and at the lateral orbital ostcotomies of the rims. The frontal bone graft is either recontoured or rotated and trimmed to establish the most normal-appearing forehead. Cutouts for the superior orbital margins are then performed and the frontal bone graft is onlayed over the advanced superior orbital bar. Microscrews secure the onlayed graft to the underlying rim. Residual temporal prominences can be resected and repositioned or "barrel staved" [11] and infractured. Posteriorly, the recontoured frontal bone is left floating.

\section{Metopic synosiosis (irigonocephaly)}

Correction of trigonocephaly involves a modification of conventional techniques (Fig. 6). A frontal craniotomy is performed, the metopic suture is resected, and the superior orbital rim is removed. Extensive recontouring of the midline portion of the rin is necessary to correct its wedge shape. Also, during its recontouring, the superior orbital bar is often fractured in half. Therefore, we prefer to resect the deformed metopic suture in its entirely, down to and including the midline of the superior orbital rim.

The superior portion of the orbital tim is then translocated laterally (Fig. 6). An appropriately contoured portion of the frontal bone graft is selected to reconstruct the forehead and onlayed over the supraotbital rim, spanning both halves (Fig. 6). Microplates and screws are used to fix in position, thereby reconstituting the superior orbital bar, while maintaining the new interorbital distance. If only a greenstick fracture of the superior orbital bar is required to correct the lateral recession, the fixation technique mentioned above may be all that is necessary. However, if extensive advancement of the lateral portion of the superior orbital bar is required, fixation with mictoplates and screws is added al the osteotomies of the lateral orbital rims (Fig. 6).

As in the other repairs, the frontal bone graft is left free of posterior fixation. Great lengths are taken, however, to rectify the bitemporal depressions associated with this deformity.

\section{Multiple synostoses}

Formulation of a tentative operative plan is helpful, but generally it is not until the calvarium is fully exposed that the true nature of the deformity becomes apparent and motivates the surgeon's imagination.

In patients requiring total vault reshaping, the stenosed sutures are first resected. If abnomal angulation or recession of the superior orbital rim is present, its mobilization and repositioning are indicated in addition to vault reshaping (Figs. 7-9). The newly contoured frontal bone graft can then be cut out and onlayed over the advanced rim. If recession or angulation of the rim is mild, it is a wasted exercise to mobilize the superior orbital bar. In these cases, the abnormal angulation of the rim can be bevelled or burred and a new superior orbital rim can be fashioned from the onlayed frontal graft.

Total cranial vault reshaping can be accomplished by a variety of techniques, but ultimately relies on surgical ingenuity to provide the best contour. Currently, we employ a combination of procedures, including barrel stave osteotomies [11], bone bending with wedge osteotomies, and bone-flap switch techniques.

\section{Study population}

Review of the records of the UCLA Craniofacial Anomalies Clinic from January 1985 to January 1990 disclosed 65 patients with syn- 

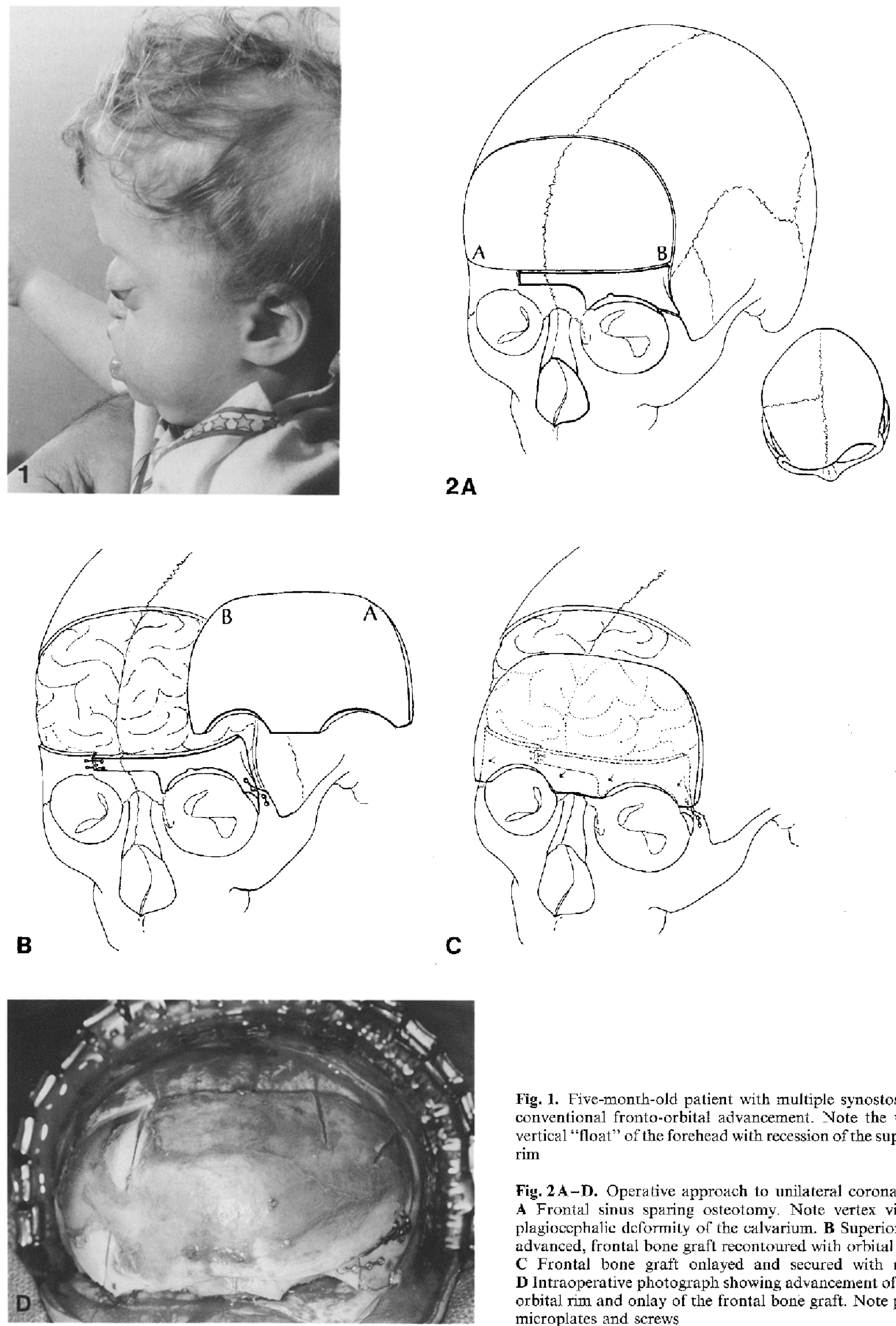

Fig. 1. Five-month-old patient with multiple synostosis following conventional fronto-orbital advancement. Vote the uncontrolled vertical "float" of the forehead with recession of the superior orbital rim

Fig. 2A-D. Operative approach to unilateral coronal synostosis. A Frontal sinus sparing osteotomy. Note vertex view showing plagiocephalic deformily of the calvarium. B Superior orbital rim advanced, frontal bone graft recontoured with orbital rims cutout. C Frontal bone graft onlayed and secured with microscrews. D Intraoperative photograph showing advancement of the superior orbital rim and onlay of the frontal bone graft. Note placement of microplates and screws 

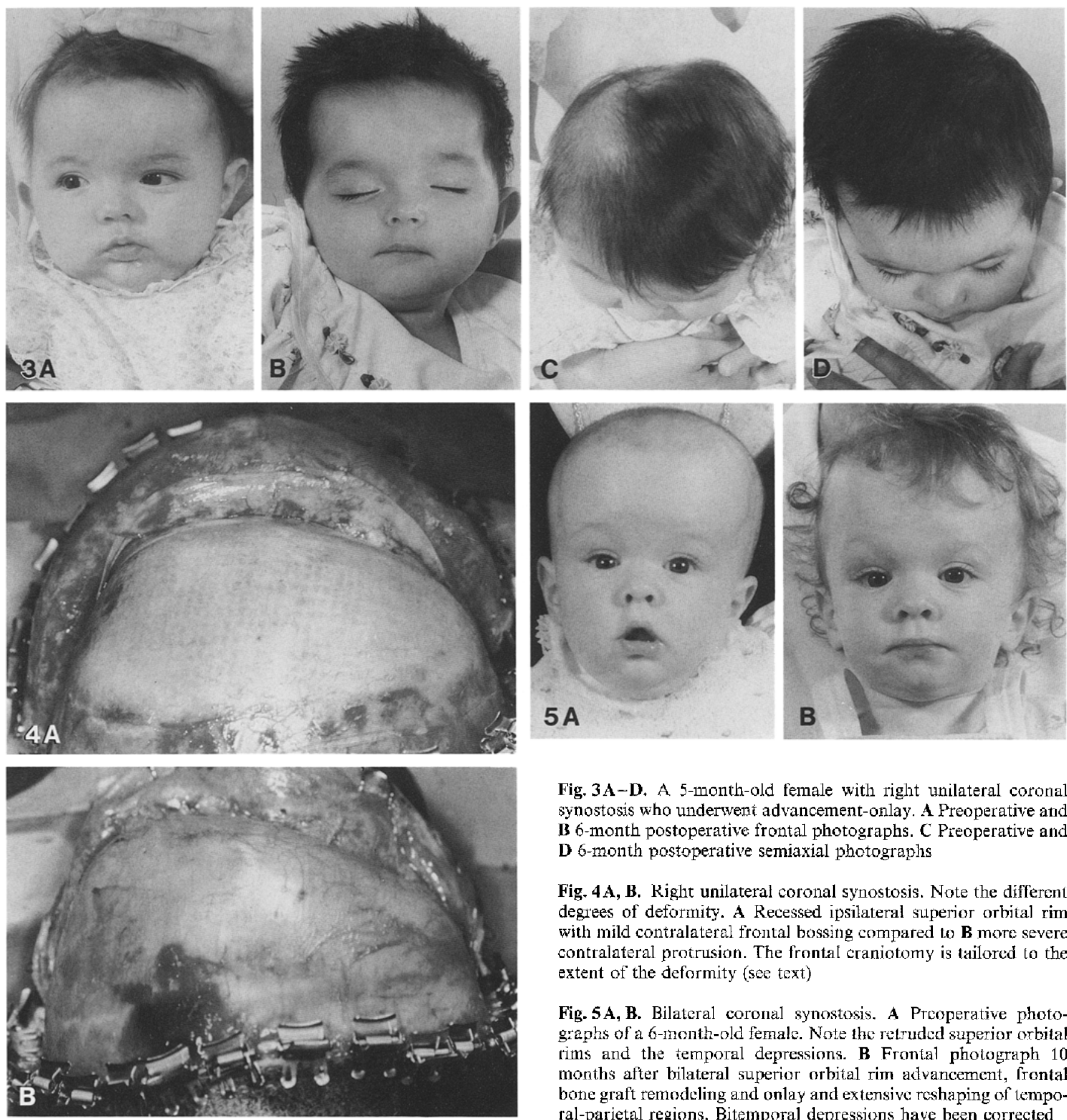

Fig. 3A-D. A 5-month-old female with right unilateral coronal synostosis who underwent advancement-onlay. A Preoperative and B 6 -month postoperative frontal photographs. C Preoperative and D 6-month postoperative semiaxial photographs

Fig. 4A, B. Right unilateral coronal synostosis. Note the different degrees of deformity. A Recessed ipsilateral superior orbital rim with mild contralateral frontal bossing compared to $\mathbf{B}$ more severe contralateral protrusion. The frontal eraniotomy is tailored to the extent of the deformity (see text)

Fig. 5A, B. Bilateral coronal synostosis. A Prcoperative photographs of a 6-month-old female. Note the retruded superior orbital rims and the temporal depressions. B Frontal photograph 10 months after bilateral superior orbital rim advancement, frontal bone graft remodeling and onlay and extensive reshaping of temporal-parietal regions. Bitemporal depressions have been corrected

dromic and nonsyndromic craniosynostosis who underwent surgical treatment. Of these, 18 patients $(28 \%)$ with nonsyudromic craniosynostosis were treated using the advancenent-onlay techmique.

The advancement-onlay procedure was performed on $12 \mathrm{fe}-$ males and 6 males whose ages ranged from $2-11$ months (mean $=5$ months). The distribution of sutural involvement was unilateral coronal synotosis $(n=10)$, bilateral coronal syluostosis $(n=3)$, metopic synostosis $(n=2)$, and multiple synostoses $(n=3)$.

\section{Analysis of operative results}

Outcome was determined by review of patient records and postoperative photographs. Surgical results were categorized by a modifi-

cation of a classification scheme previously proposed by Whitaker et al. [12]. Patients were considered to have a poor to fair result (group I) if major osteotonies or bone-grafting procedures duplicating or exceeding in extent the original uperation were necded or had been performed. If no imperfections were noted or only minor, resiclual deformities were present, patients were classified as having a good-to-cxcellent result (group 1I). Patients with minor residual deformities requiring limited extracranial recontouring procedures were itacluded in group II.

\section{Results}

Follow-up time in this series ranged from 6 to 60 months (mean $=2.6$ years). There were no serious postoperative 


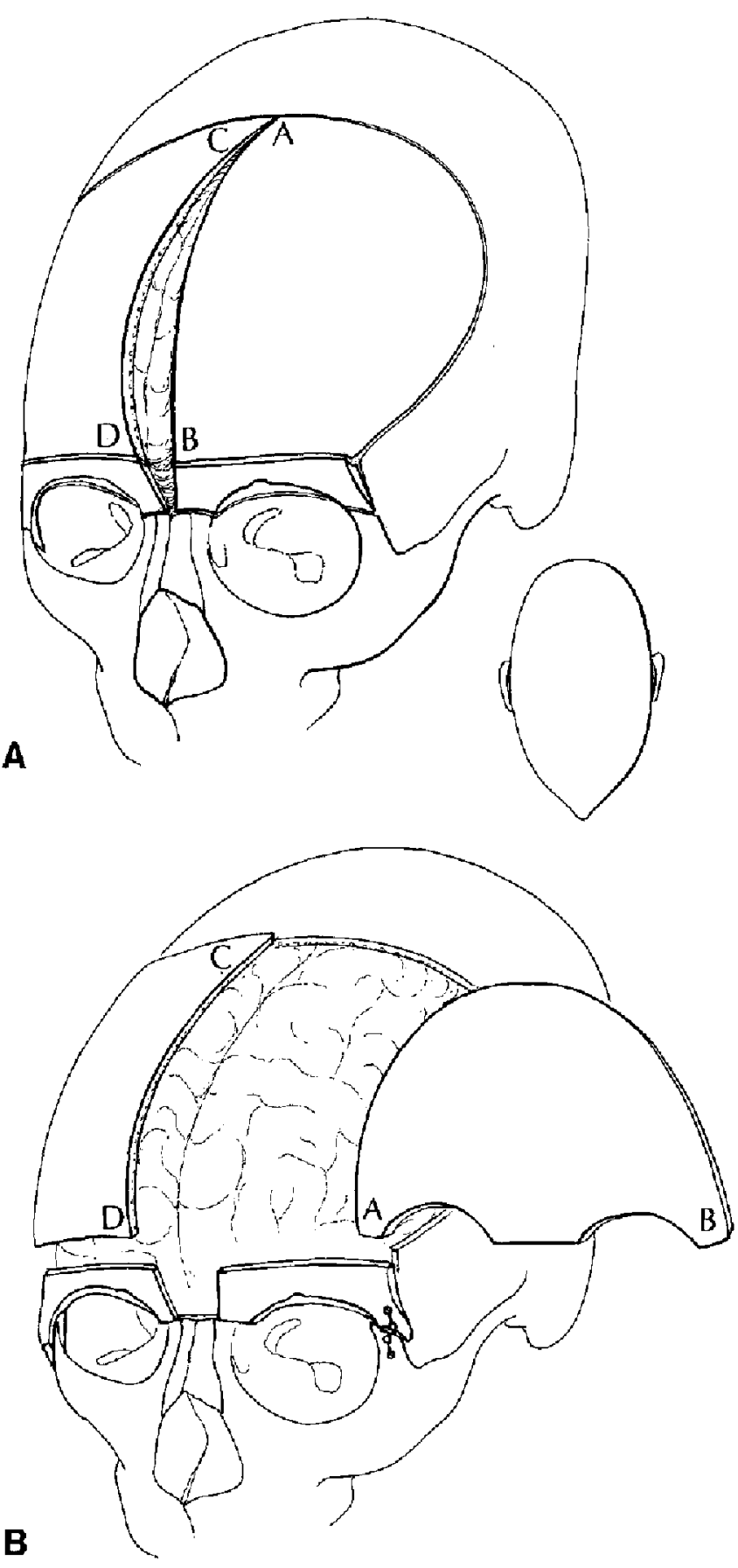

Fig. 6A-D. Operative approach to metopic synostosis. A Resection of involved suture, ostcotomies of superior orbital rims and frontal bone. B Advaneement of rims. especially at their lateral aspects. Hypotelorbitism, if present, is corrected C Recontoured

complications. Surgical results were good to excellent in $17 / 18$ patients $(94 \%)$ and poor to fair in $1(6 \%)$. Mild residual deformities, however, were found in 5 patients and consisted of: superior lateral orbital rim recession $(n=3)$; temporal depression $(n=5)$; and decreased height of the ipsilateral palpebral fissure $(n=1)$. Only 1 patient with a Kleeblattschädẹl deformity, who developed turribrachycephaly secondary to unoperated bilateral lambdoidal synostosis, required major revisions. Another pa-
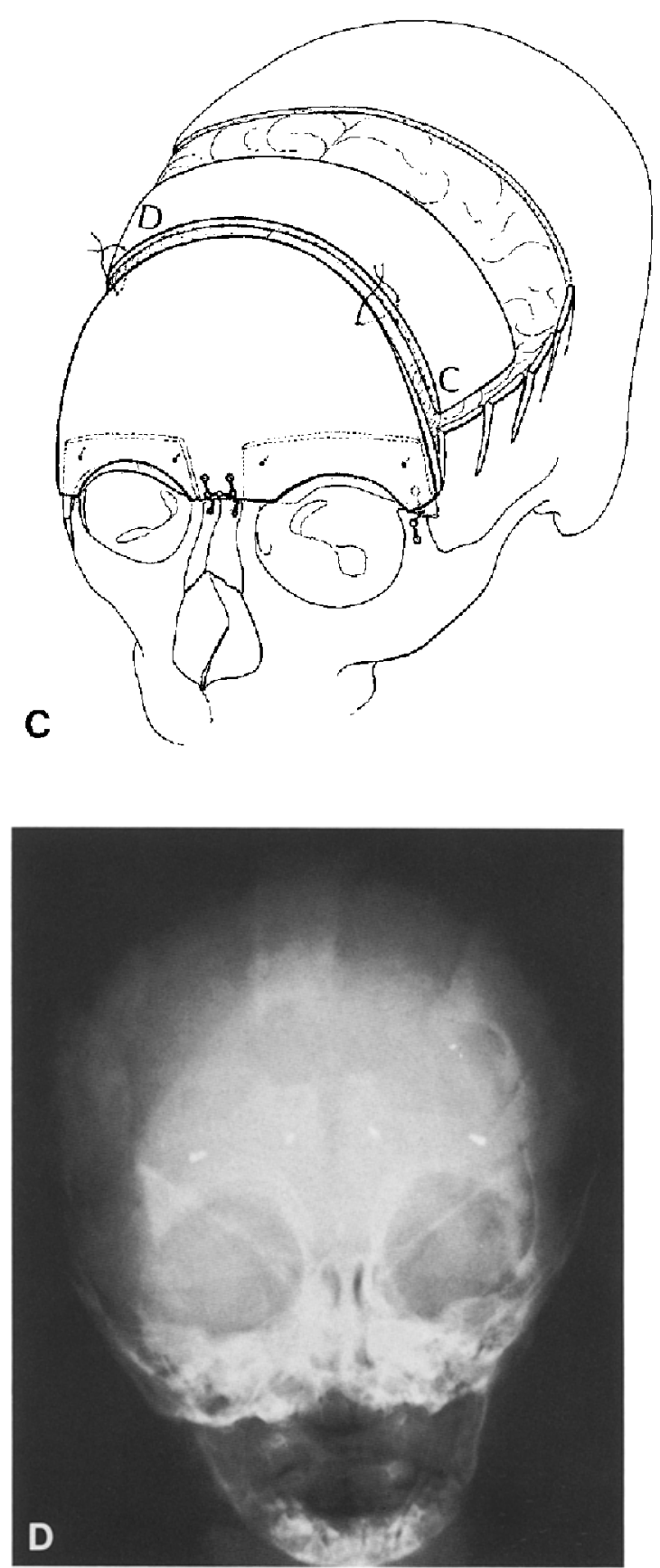

frontal bone graft onlay reconstituting superior orbital bar. D Postoperative radiograph showing supcrior orbital bar split and expanded

tient with trigonocephaly underwent a minor, extracranial recontouring procedure. LeFort III advancement is anticipated in 2 patients with multiple syuostoses and associated midface retrusion. To date, no gross disturbances in craniofacial growth related to rigid fixation have been observed and clinically detectable resynostosis has not occurred in this subgroup.

Wire osteosynthesis was utilized in 7 patients, while rigid fixation with microplates and screws was employed 


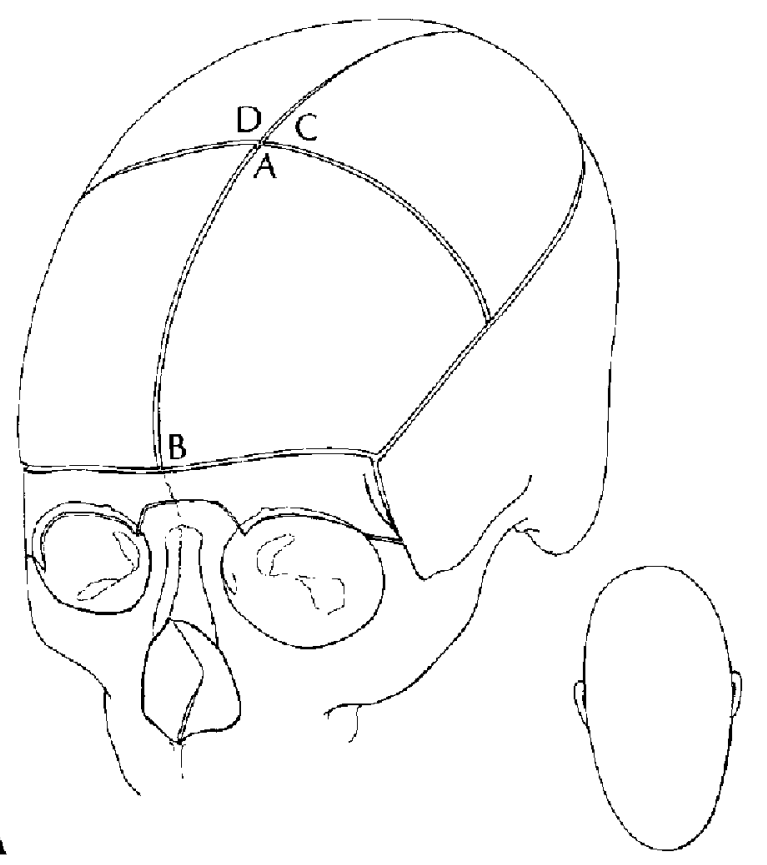

A

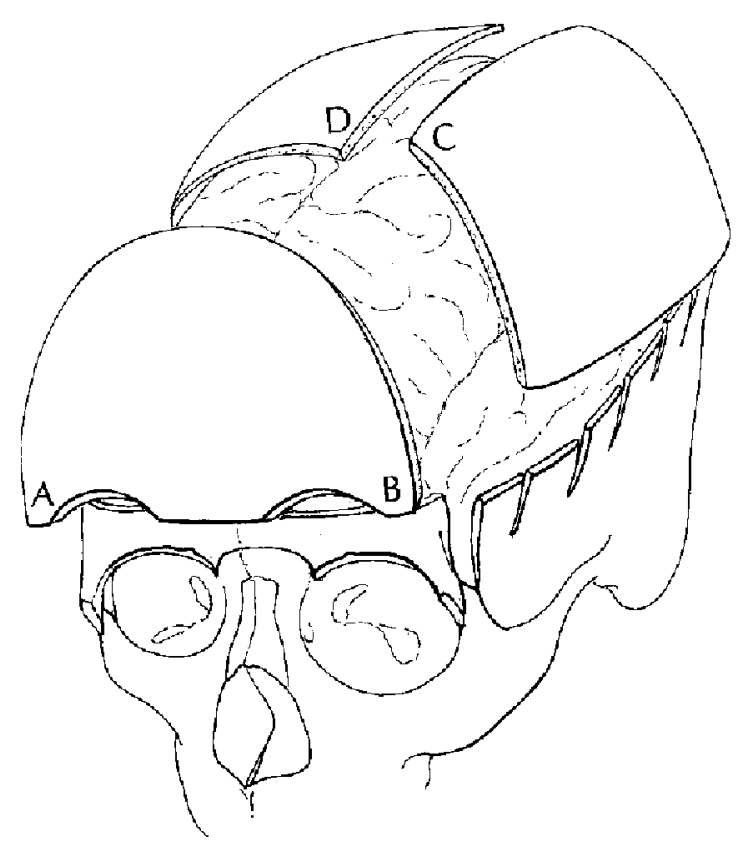

B

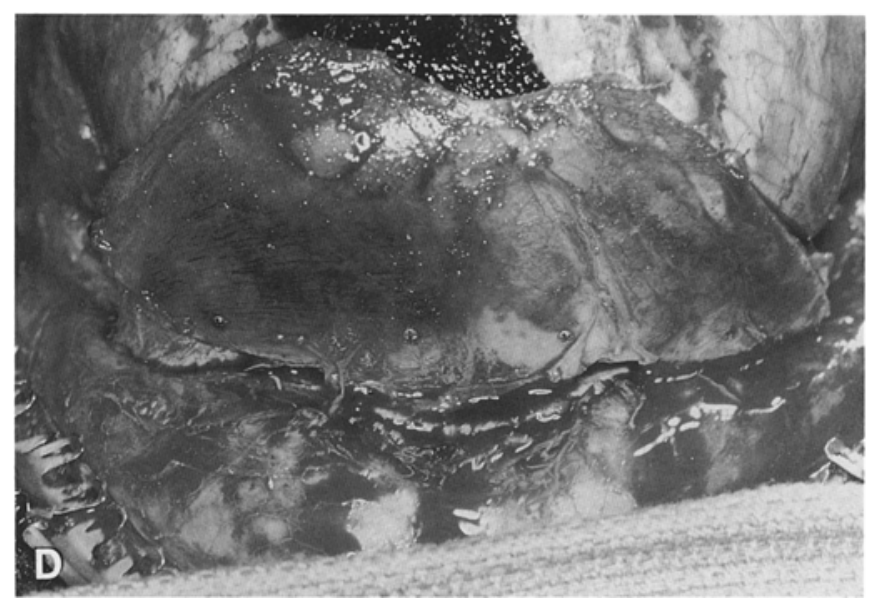

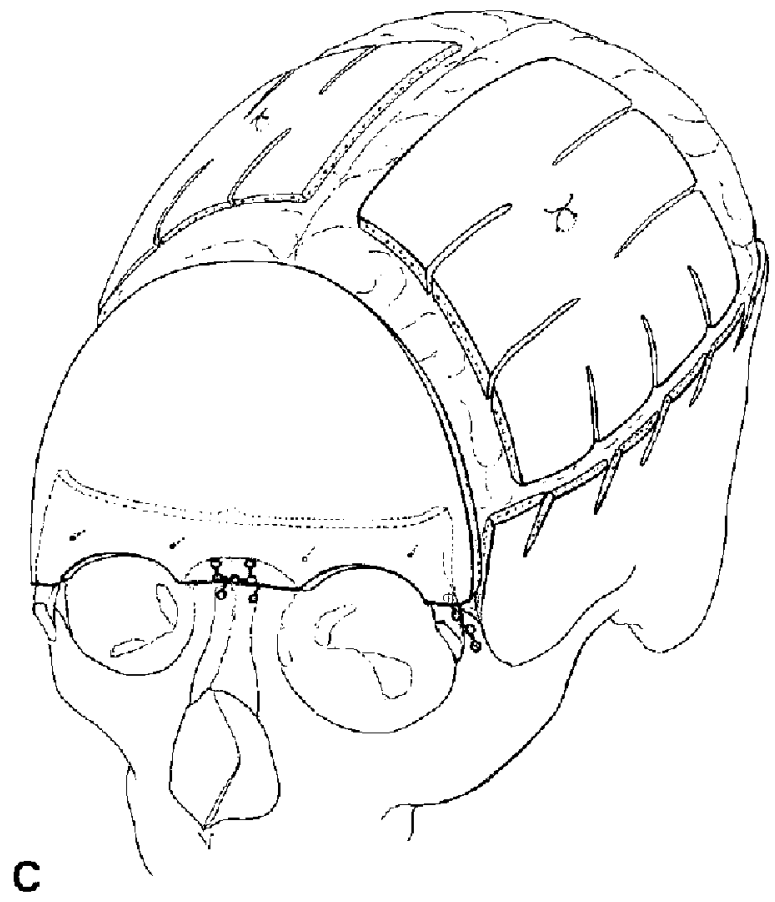

Fig. 7 A-D. Opcrative approach to multiple synostoses. A Frontal sinus sparing osteolomies for seaphocephaly associaled with superior orbital rim recession and severe midface retrusion. B Advanced superior orbital rim, temporal-parietal barrel-stave osteotomies. C Onlayed, remodeled frontal bone graft and recontoured parietal bone grafts. D Intraperative photographs showing onlayed frontal bone graft rigidly fixed to underlying superior orbital bar

in the remaining 11 . Interestingly, of the 5 pationts with residual deformities following reconstruction, wire was used in 2 and microplates and screws in 3.

\section{Discussion}

Doubt as to the safety and efficacy of treatment of craniosynostosis no longer exists; thus, attention can be focuscd on other priorities in the management of such patients. Accurate and detailed information regarding longterm results of craniofacial surgery is difficult to procure. Disappointment in the late aesthetic results in some cases of nonsyndromic craniosynostosis treated by conventional fronto-orbital remodeling led us to re-evaluate our technique. Others have also noted less than ideal correction in patients with unilateral coronal synostosis using both unilateral and bilateral approaches [1]. Contour irregularities in the temporal and/or lateral forehead region prompted these authors to call for more stringent attention to these areas.

In an attempt to improve the stability of shifted skeletal segments and the consistency of results of conventional fronto-orbital advancement, a simplified tcchnique of advancement-onlay was developed. To the standard techniques is added fabrication of a new, superior orbital rim, using the frontal bone graft as an onlay over the advanced (original) superior orbital bar. The technique re- 

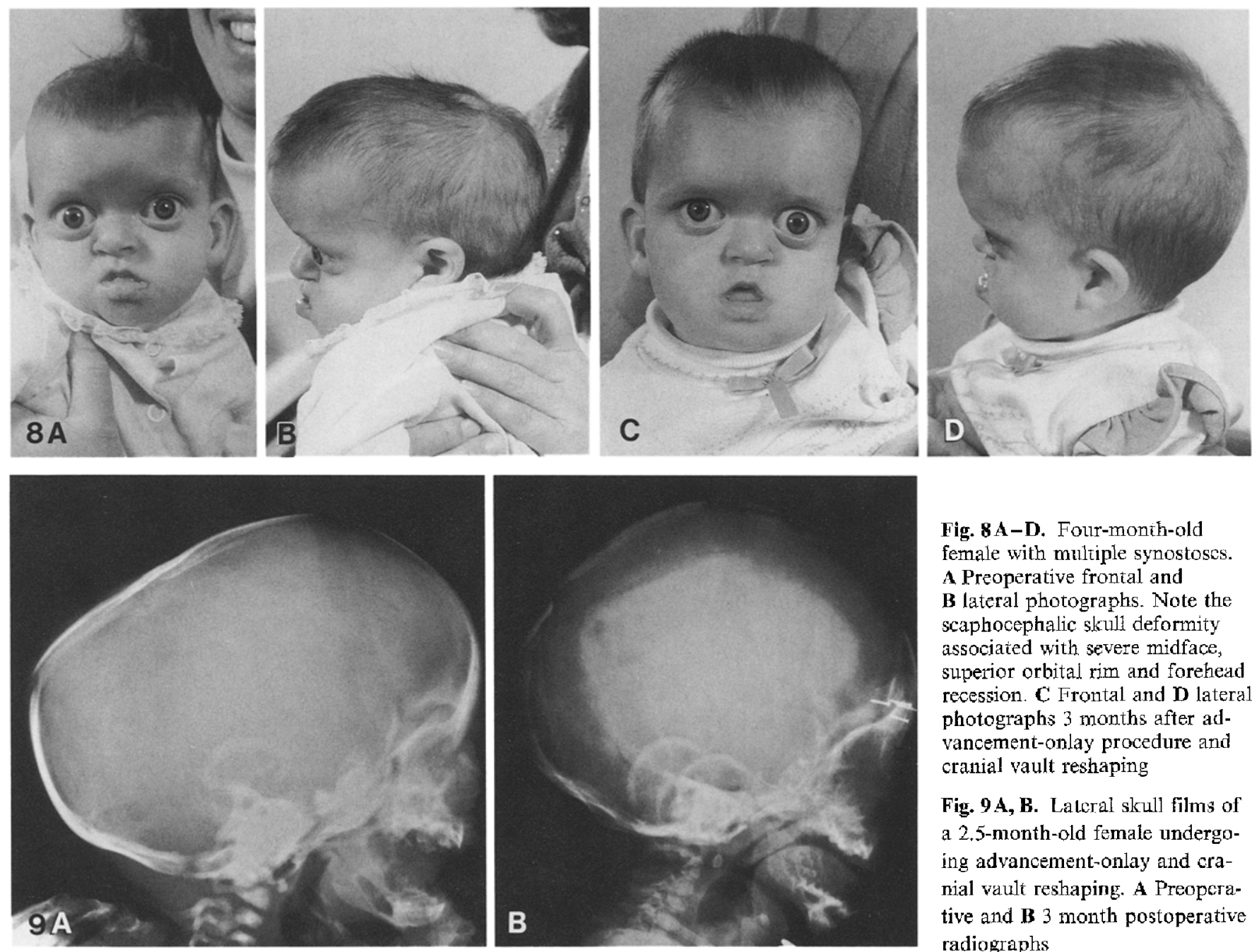

Fig. 8A-D. Four-month-old female with multiple synostoses. A Preoperative frontal and B lateral photographs. Note the scaphocephalic skull deformity associated with severe midface, superior orbital rim and forehead recession. C Frontal and $\mathbf{D}$ lateral photographs 3 months after advancement-onlay procedure and cranial vault reshaping

Fig. 9 A, B. Latcral skull films of a 2.5-month-old female undergoing advancement-onlay and cranial vault reshaping. A Preoperative and $\mathbf{B} 3$ month postoperative radiographs

captures an earlier procedure developed by Rougerie, one of the neurostrigeons working with Tessier [4].

According to Marchac, Rougerie's original technique consisted of onlaying the frontal bone over an undisturbed superior orbital ridge [4]. Unfortunately, the onlay procedure by itself rarely suffices. However, when combined with fronto-orbital advancement the advantages are complementary. The superior rim can be advanced, repositioned caudad or cephalad, angulated or translocated laterally or medially. The frontal bone onlay provides uniform contour and stability of the repositioned segments. Projection can be maintained and is ensured with the use of microplates and screws. Thus, the tendency toward retrodisplacement, rotation and/or vertical float of the superior orbital bar with closure of the coronal flap (especially after sizable anterior advancements) is resisted. In addition, fancy carpentry and selfretaining osteotomies are eliminated by the use of rigid microfixation, allowing more latitude when correcting temporal depressions. Advancement-onlay, especially in concert with microfixation, is a reliable technique, which simplifies the treatment of patients with both nonsyndromic and syndromic craniosynostosis.

Potential criticism of this technique is directed not so much against the use of onlay frontal bone grafting, but against the employment of microplates and screws for rigid fixation. The effect of rigid fixation on the growth of the craniofacial skeleton is not entirely clear. Wong et al. [Wong L, Dufresne DR, Richtsmeier JM, Manson PM (1989) The effect of rigid fixation on the growing craniofacial skeleton. Presented at the 58th Annual Scientific Session of the American Society of Plastic and Reconstructive Surgeons, San Francisco, Calif, 1989] studied craniofacial growth in $66 \mathrm{New}$ Zealand white rabbits operated on at 6-7 weeks of age. Skull-shape changes were quantitated in three dimensions by computer digitization of analomic landmarks in threee dimensions. Necropsy 12 weeks after operation showed local growth restriction when plates and screws were placed across the coronal suture. In a similar study from our institution, Resnick and coworkers [Resnick JI, Kinney BM, Kawamoto HK Jr (1989) The effect of rigid internal fixation on cranial growth. Presented at the 39 th Annual Meeting of the Califomia Society of Plastic Surgeons, Maui, Hawaii, 1989] plated across the right coronal suture in 6-weck-old rabbits.

Animals were killed 18 weeks postoperatively and cranial growth was assessed by direct osteometry on dry skull preparations. Statistically significant decreases in the lambdoid-frontal distance were found in the plated 
group compared to nonplated controls. Lin and colleagues [Lin KY, Bartlett SP, Yaremchuk MJ, Grossman R, Falion M, Whitaker LA (1989) The effects of rigid lixation on the developing craniofacial skeleton. Presented at the 58th Annual Scientific Session of the American Society of Plastic and Reconstructive Surgeons, San Francisco, Calif, 1989], using cats as the surgical model, compared rigid fixation to wire osteosynthesis after orthotopic replacement of an ostcotomized segment, which included the superior orbital rim and frontal bone. Differences in growth between the above two groups were negligible. However, when compared to shammed controls, there appeared to be some decrease in skull height and length, indicating restriction.

We have purposely limited fixation techniques to the anterior bony elements, leaving the frontal bone floating and the craniectomy across the coronal sutures wide open. Similarly, in cases of multiple synostoses, all involved posterior sutures are resected, while vault reshaping is accomplished by recontouring calvarial fragments, which are left floating or anchored to each other or the dura with absorbable suture material. Thus, in no instance is a plate placed across a cranial suture. Although follow-up time in this series is only 2.6 years, resynostosis has not been detected nor have clinically apparent craniofacial growth disturbances been observed.

\section{Conclusion}

Eighteen patients are reported in whom an improved technique (advancement-onlay) has been utilized to treat craniosynostosis. When combined with the use of rigid fixation with microplates and screws, temporal struts are eliminated and uncontrolled "float" of the forehead is prevented. Acsthetic outcome has been generally excel- lent. No evidence of resynostosis has occurred and clinically apparent growth disturbances have not been observed over a mean follow-up time of 2.6 years.

\section{References}

1. Bartlett SP, Whitaker LA, Marchac D (1990) Operalive treatment of isolated eraniofacial dysustosis (plagiocephal): a comparison of the unilateral and bilateral techniques. Plast Reconstr Surg 85:677

2. Marchac D (1985) Early surgery in craniofacial synostosis. In: Caronni EP (ed) Craniofacial surgery. Little, Brown \& Co, Boston, pp 246-254

3. Marchac D, Renier D (1978) Lefront flottant: traitement precoce des facio-craniostenoses. Ann Chir Plast 24:121

4. Marchac D, Renier D (1982) Craniofacial surgery for craniosynostosis. Little, Brown \& Co, Boston

5. Marsh JL (1987) The anatomy of the cranio-orbital deformities of craniosynostosis: insights from 3-D images of CT seans. Clin Plast Sutg 14:49

6. Marsh JL, Vannier MW (1985) Craniofacial deformities. Comprehensive care for craniofacial deformities. Mosby, St Louis, Mo, pp 121-172

7. Marsh JL, Vannier MW (1986) Cranial base changes following surgical treatment of the craniosynostosis. Cleft Palate J [Suppl] 9

8. Marsh JL, Gado MG, Vannier MW, Stevens WG (1986) The osseous anatomy of unilateral coronal synostosis. Cleft Palate J 23:87

9. McCarthy JG (1985) Early surgery in craniofacial synostosis. In: Caronni EP (ed) Craniofacial surgery. Little, Brown \& Co, Boston, pp $232-245$

10. MeCarthy JG, Epstein FJ, Wood-Smith D (1990) Craniosynostosis. In: McCarthy JG (ed) Plastic surgery. Saunders, Philadelphia, pp 3013-3053

11. Pershing JA, Edgerton MT, Parks TS, Jane JA (1987) Barrel Stave osteotomy for corrcction of turribrachycephaly craniosynostosis deformitics. Ann Plast Surg 18:488

12. Whitaker LA, Bartlet SP, Shut L, Bruce D (1987) Craniosynostosis: an analysis of the timing, treatment and complications in 164 conseculive patients. Plast Reconstr Surg 80:195 